\title{
Synthesis and Characterization of Aurantiol Schiff Base, Relationship Between Synthesis Time and Some Physical Properties
}

\author{
CANDRA IRAWAN ${ }^{1}$, SUCI INDRYATI', ENDANG SRI LESTARI ${ }^{2}$, \\ ARINZANI HIDANINGRUM ${ }^{3}$ and SUPRIYONO ${ }^{1 *}$
}

'Department of Chemical Analysis, Politeknik AKA Bogor, Bogor 16154, Indonesia.

${ }^{2}$ Department of Industrial Waste Treatment, Politeknik AKA Bogor, Bogor 16154, Indonesia.

${ }^{3} \mathrm{PT}$. Nilam Widuri, Bogor Indonesia.

${ }^{*}$ Corresponding author E-mail: supriyono272@gmail.com

http://dx.doi.org/10.13005/ojc/340142

(Received: Octuber 24, 2017; Accepted: Novmeber 25, 2017)

\begin{abstract}
Aurantiol or hydroxycitronellal-methyl anthranilate schiff base was a common compound added in the manufacture of fragrance. The addition of aurantiol to the fragrance, made the fragrance more stable and the resulting odor can last longer. Generally aurantiol was prepared by reflux technique with stirring and addition of acid catalyst, which then was continued by recrystallization to purify the resulted aurantiol. This method was ineffective and required a high cost, so it needed a more effective and efficient manufacturing techniques, namely simple condensation technique. This technique consisted of two steps: the synthesis step, and the characterization. The synthesis step was began by weighing of the raw material were hydroxycitronellal and methyl anthranilate. The synthesis of aurantiol was carried out by heating at $90 \pm 5{ }^{\circ} \mathrm{C}$, and with variation of synthesis time for $15 \mathrm{~min}, 30 \mathrm{~min}, 1 \mathrm{~h}, 2 \mathrm{~h}, 3 \mathrm{~h}$, and 4 hours. The characterization included chemical composition, organoleptic test, refractive index, density, specific gravity determination. Organoleptic tests included odor and color test. The measurement of refractive index was performed by refractometer, the chemical composition was performed by gas chromatography-mass spectrometer, while density and specific gravity were performed by pycnometer. From the experimental results, we got the optimum synthesis time that was between $30 \mathrm{~min}$. to $1 \mathrm{~h}$, with aurantiol products of $77.57 \%$. In this optimum condition, the resulted aurantiol had odor test results: floral balsamic, sweet, orange blossom; color test: light yellow to greenish yellow; and refractive index, density, specific gravity were 1,543, $1.052 \mathrm{~g} / \mathrm{mL}, 1,054$ respectively. Based on the experimental results, it can be concluded that the synthesis of aurantiol with simple condensation technique has been successfully done, with the highest aurantiol yield of $77.57 \%$ with optimum synthesis time of 30 minutes to 1 hour. Therefore, this optimum condition can be used as a reference for the synthesis of aurantiol on an industrial scale.
\end{abstract}

Keywords: Schiff base, Aurantiol, Hydroxycitronellal, Methyl anthranilate, Fragrance.

This is an $\mathbf{C}$ Open Access article licensed under a Creative Commons Attribution-NonCommercial-ShareAlike 4.0 International License (https://creativecommons.org/licenses/by-nc-sa/4.0/ ), which permits unrestricted NonCommercial use, distribution and reproduction in any medium, provided the original work is properly cited. 


\section{INTRODUCTION}

Fragrance is a mixture of several compounds that each compound works in accordance with its properties to produce aromatic compounds. ${ }^{1-3}$ Important properties of fragrance include volatility, polarity, and stability. Volatility is a key element in combining aromatic compounds. High volatile materials will evaporate first, top notes in perfumes, while materials with moderate volatility and resistance are called modifiers or middle notes, and materials with low volatility are base notes or bottom notes. ${ }^{4}$ Ones of the compounds added to the fragrance to produce qualified fragrance is a Schiff base. Schiff base is a compound formed from condensation reaction between aldehyde and primary amine and produce water as byproduct. ${ }^{5-6}$ Amines commonly employed in the fragrance industry are methyl anthranilate and ethyl anthranilate, whereas aldehyde compounds commonly used in the fragrance are alkyl or aldehyde aromatics, terpen aldehydes, such as hydroxycitronellal. ${ }^{7}$ as follows:

The reaction of Schiff base formation the fact that Schiff base can improve chemical stability and resilience of fragrance blends. There are many types of Schiff base used in the fragrance industry, including jasmea, verdantiol, cyclantine, indolene, helioforte aquanhtral, vertosine aqrumea ligantraal, agrea, decimea, nonimea, ocmea, isonomilat, amandolene, canthoxalia, acaciol, and most often used in the industry is aurantiol, the schiff base formed from a mixture of hydroxycitronellal and methyl anthranilate. ${ }^{8}$

Aurantiol has the IUPAC nama: methyl-N3,7-dimethyl-7-hydroxyoctyliden anthranilate, and several trade names such as aurantiol, auriol, auranol, auralva, anthralal, aurangeol, aurantine, and bigariol. Aurantiol has a molecular formula $\mathrm{C}_{18} \mathrm{H}_{27} \mathrm{NO}_{3}$, so the molecular weight of $305.43 \mathrm{~g} / \mathrm{moL} .{ }^{4}$

In this study, we prepared aurantiol by simple condensation technique with various syntheses times. The optimum synthesis time was investigated and will be discussed here in.

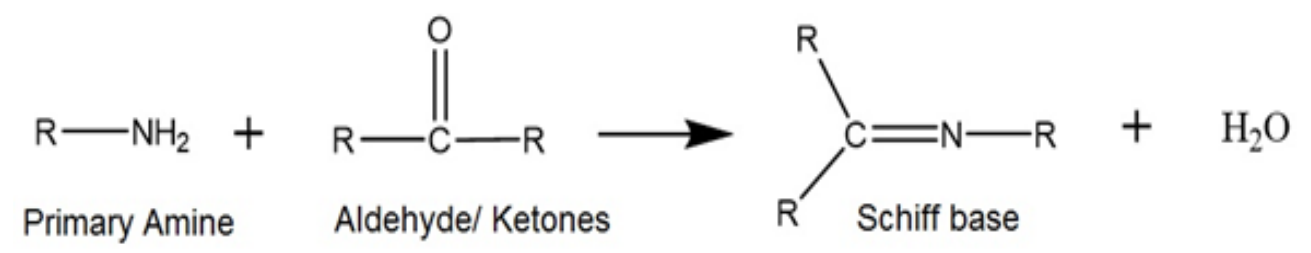

In general, methyl anthranilate produce a schiff base in the form of solid or yellow viscous liquid. The reaction of the formation of schiff base is usually not perfect, so that the color of schiff base does not become dark. Schiff base has a large molecular weight compared to other fragrance compounds, so the Schiff base is difficult to dissolve in water and has good resistance. If there are aldehyde and methyl anthranilate, it will react spontaneously to form schiff base, and water as a by-product, resulting in turbidity and separated into two phases. One method used to remove a byproduct of water is by vacuum at high temperature and atmospheric pressure..$^{4,7}$

Sell (2006) argues that the importance of Schiff base in the fragrance industry is based on

\section{EXPERIMENTAL METHODS}

The experimental methods consisted of two steps: the synthesis step, and the characterization. The synthesis step was begun by weighing of raw materials that were hydroxycitronellal and methyl 
anthranilate. The aurantiol synthesis was carried out at a temperature of about $90 \pm 5^{\circ} \mathrm{C}$ with modification of time for $15 \mathrm{~min}, 30 \mathrm{~min}, 1 \mathrm{~h}, 2 \mathrm{~h}, 3 \mathrm{~h}$, and 4 hours. The characterizations consisted of chemical composition, organoleptic tests, refractive index, density and specific gravity determination.
Organoleptic tests included odor and color test by Flavor \& Texture Profile test method. Measurement of refractive index was using refractometer, density and specific gravity using pycnometer, and chemical composition using Gas Chromatography-Mass Spectrometer (GC-MS). ${ }^{9}$

Table. 1: Analysis condition of GC-MS

\begin{tabular}{|c|c|}
\hline & Description \\
\hline GC-MS Type & Agilent Technologies 5975C inert MSD \\
\hline Column & $\begin{array}{l}\text { Polar capillary column: HP-5 } 5 \% \text { Phenyl Methyl Siloxan } \\
\text { Length }=30 \mathrm{~m} \text {; Internal diameter }=0.25 \mathrm{~mm} \text {; film thickness }=0.25 \mu \mathrm{m}\end{array}$ \\
\hline Carrier gas & Helium \\
\hline Carrier gas pressure & 7,05 Psi \\
\hline Detector & Mass spectrometer detector \\
\hline Injector temperature & $100^{\circ} \mathrm{C}$ \\
\hline Injection volume & $0,2 \mu \mathrm{L}$ \\
\hline Injection technique & Split \\
\hline Split ratio & $80: 1$ \\
\hline \multicolumn{2}{|c|}{ Temperature program (column) } \\
\hline Initial temperature & $100^{\circ} \mathrm{C}$, hold for $5 \mathrm{~min}$. \\
\hline Temperature rate & $15^{\circ} \mathrm{C} /$ minute \\
\hline Final temperature & $250^{\circ} \mathrm{C}$, hold for $5 \mathrm{~min}$. \\
\hline Interval & $20 \min$. \\
\hline
\end{tabular}

Density and specific gravity were calculated by the following formula:

$$
\rho=\frac{m}{v}
$$

$\begin{array}{ll}\text { Where: } & (\rho) \quad \text { : density }(\mathrm{g} / \mathrm{mL}) \\ \mathrm{M} & : \text { mass }(\mathrm{g}) \\ \mathrm{V} & \text { : volume }(\mathrm{mL})\end{array}$

Where: SG

$$
S G=\frac{\rho \text { compound }}{\rho \text { water }}
$$

: Specific gravity

$\rho$ compound : The density of the compound $(\mathrm{g} / \mathrm{mL})$

$\rho$ water : Water density $(\mathrm{g} / \mathrm{mL})$

The composition of the constituent compound was determined using Gas Chromatography-Mass Spectrometer (GC-MS), which aurantiol $10 \%$ in ethanol was injected, then the result of aurantiol fragmentation was determined by the existing library. The condition of GC-MS as in Table 1.

\section{RESULTS AND DISCUSSION}

\section{Synthesis of Aurantiol}

Aurantiol was obtained by reacting hydroxycitronellal and methyl anthranilate, with a simple condensation technique at $(90 \pm 5){ }^{\circ} \mathrm{C}$ with synthesis time of $15 \mathrm{~min}, 30 \mathrm{~min}, 1 \mathrm{~h}, 2 \mathrm{~h}, 3 \mathrm{~h}$ and 4 $h$, respectively. The result of the formation of aurantiol with various synthesis times were as shown in Figure. 1.

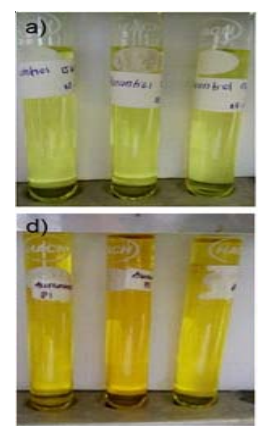

Fig. 1. Color of aurantiol product with various synthesis time: a) $15 \mathrm{~min}$, b) $30 \mathrm{~min}$, c) $1 \mathrm{~h}$, d) $2 \mathrm{~h}$, e) 3 hours, f) 4 hours 
In addition to speed up the reaction, heating also serve to eliminate byproducts of water and to prevent the formation of a turbid aurantiol and separated into two phases. The aurantiol formation reaction was as follows: ${ }^{10}$<smiles>CC(CC=O)CCCC(C)(C)O</smiles>

Hydroxycitronellal<smiles>COC(=O)c1ccccc1N</smiles>

TIC: AURANTOL1SMP3 Didatams

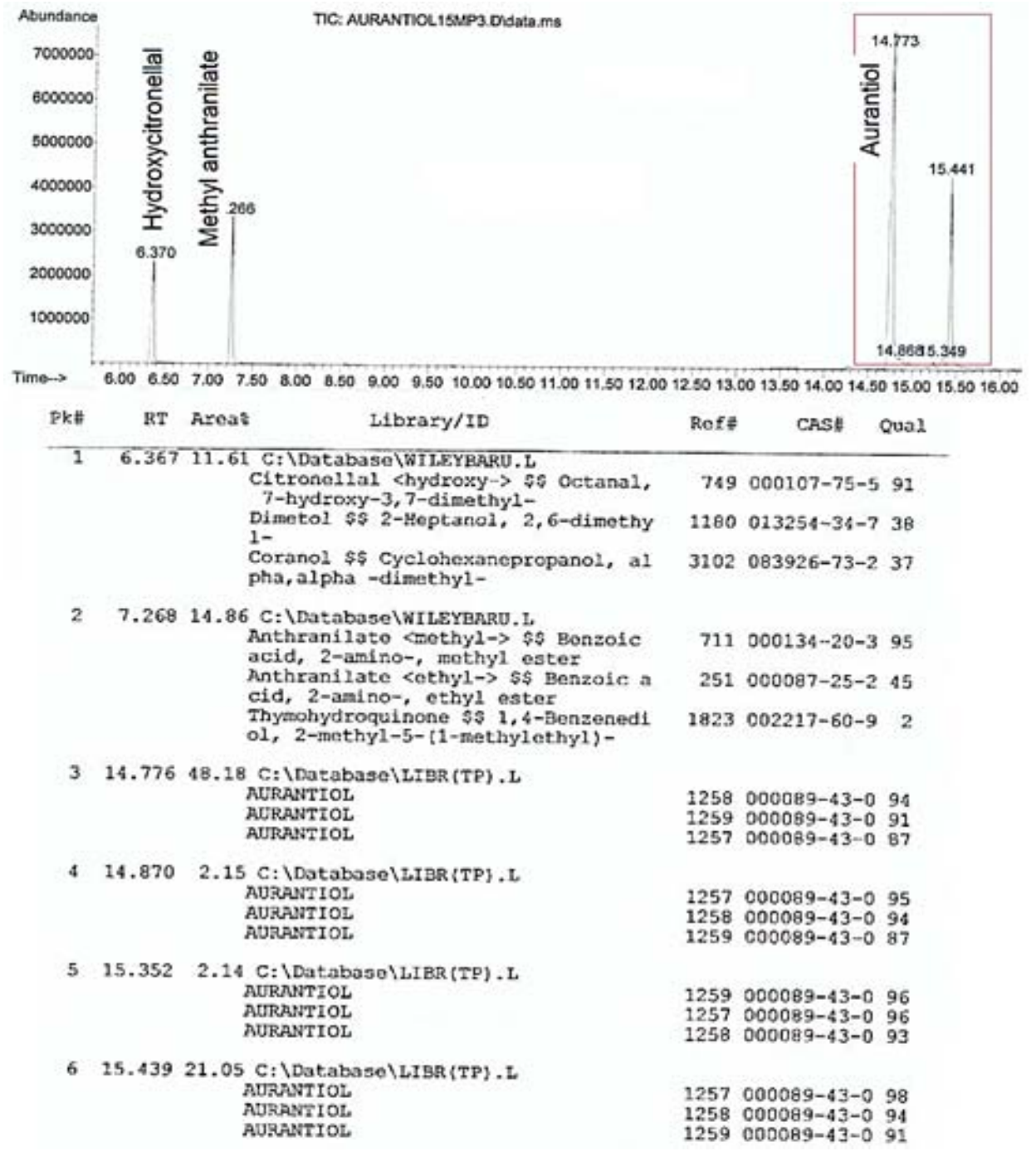

Fig 2. GC-MS chromatogram of aurantiol with 15 minute synthesis time 
To prove that aurantiol was actually formed, an analysis with GC-MS was performed. Based on GC-MS chromatogram in figure 2, it was seen that the aurantiol peak was at 14.773 and 15.441 minutes. The presence of two aurantiol peaks indicated that aurantiol had 2 isomers namely $d$-aurantiol and -aurantiol $^{11}$, so total aurantiol was the sum of $d$-aurantiol and l-aurantiol. In addition to the aurantiol peak, there were also hydroxycitronellal and methyl anthranilate peaks at 6.367 and 7.268 minutes, respectively. This showed that the aurantiol formation reaction was an equilibrium reaction, so to increase the amount of aurantiol can be done by evaporating water so that the equilibrium shifted to the right. The results of aurantiol analysis with GC MS at various synthesis times were as follows:

Table. 2: Results of aurantiol analysis with GC MS

\begin{tabular}{lccc}
\hline Synthesis Times & Hydroxycitronellal & $\begin{array}{c}\text { \% Area }- \text { GC Yield } \\
\text { Methyl anthranilate }\end{array}$ & Aurantiol \\
\hline 15 min. & 11.61 & 14.86 & 73.53 \\
30 min. & 9.53 & 12.90 & 77.57 \\
$1 \mathrm{~h}$ & 10.00 & 12.96 & 77.04 \\
$2 \mathrm{~h}$ & 8.36 & 25.68 & 65.95 \\
$3 \mathrm{~h}$ & 9.29 & 20.67 & 70.03 \\
$4 \mathrm{~h}$ & 9.45 & 24.43 & 66.12 \\
\hline
\end{tabular}

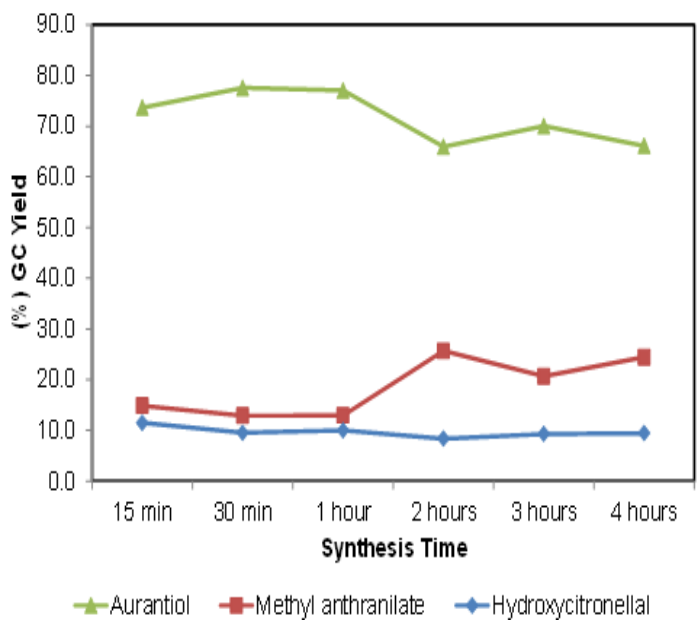

Fig. 3. The relationship between aurantiol yield and synthesis time

\section{Characterization of Aurantiol Odor Test}

One of the physical tests for checking the quality of aurantiol was the odor test. The odor test was performed by six trained panelists. The odor test results were shown in Table 3.

The odor of aurantiol came from the constituent compounds which were aldehyde and amine. Floral odor came from aldehyde compounds in the form of hydroxycitronellal while sweet and orange blossom odor was obtained from methyl anthranilate. The longer synthesis time of aurantiol, the amount of citronellal it became less so that the odor of floral it became disappear, on the contrary the longer synthesis time, the amount of methyl anthranilate it became more so that the odor of

Table. 3: Result of odor test of Aurantiol

\begin{tabular}{cc}
\hline Synthesis times & Odor \\
\hline $15 \mathrm{~min}$. & Floral, sweet, orange blossom \\
$30 \mathrm{~min}$. & Floral balsamic, sweet, orange blossom, \\
$1 \mathrm{~h}$ & Floral green, sweet, orange blossom, \\
$2 \mathrm{~h}$ & Floral, orange blossom, sweet (more jasmin) \\
$3 \mathrm{~h}$ & Floral, orange blossom, sweet, tuberose \\
$4 \mathrm{~h}$ & Floral, orange blossom \\
\hline
\end{tabular}


orange blossom became dominant. Considered factor in the odor test of fragrance or fragrance raw materials was the volatility. High volatile materials will evaporate first, top notes on perfume, while materials with the medium volatility and resistance were called modifiers or middle notes, and materials with the lowest volatility or most durable were base notes or bottom notes. In aurantiol, the top note odor was floral, the middle note was sweet, and the bottom note was orange blossom. With synthesis time of $30 \mathrm{~min}$. was formed a floral balsamic odor, while with $1 \mathrm{~h}$ synthesis time was formed a floral green odor, derived from hydroxycitronellal reactants. With $2 \mathrm{~h}$ synthesis time, there was

Therefore it can be concluded that the longer synthesis time, the top note odor will be lost so that the remaining odor was the bottom note odor that was orange blossom.

\section{Color Test}

The color test was also a physical test that becomes an important parameter of aurantiol formation. The color test was performed by a trained panelist, and obtained results as in Table. 4.
Based on table 4 above, it was seen that aurantiol made with synthesis time of $15 \mathrm{~min} .30$ min. and $1 \mathrm{~h}$ produced a light yellow color, while with a longer synthesis time of 2 hours, 3 hours and $4 \mathrm{~h}$ produced a darker color.

Table. 4: Results of aurantiol color test

\begin{tabular}{lc} 
Synthesis time & Color \\
\hline $15 \mathrm{~min}$ & Light yellow \\
$30 \mathrm{~min}$ & Light yellow - greenish yellow \\
$1 \mathrm{~h}$ & Greenish yellow \\
$2 \mathrm{~h}$ & Dark yellow \\
$3 \mathrm{~h}$ & Orange \\
$4 \mathrm{~h}$ & Orange \\
\hline
\end{tabular}

Refractive index, density and specific gravity Test The measurement results of refractive index, density and specific gravity of aurantiol as shown in table 5 below. According to Panten (2002), hydroxycitronellal density was $0.9220 \mathrm{~g} / \mathrm{mL}$, methyl anthranilate was $1.1682 \mathrm{~g} / \mathrm{mL}$, and aurantiol was
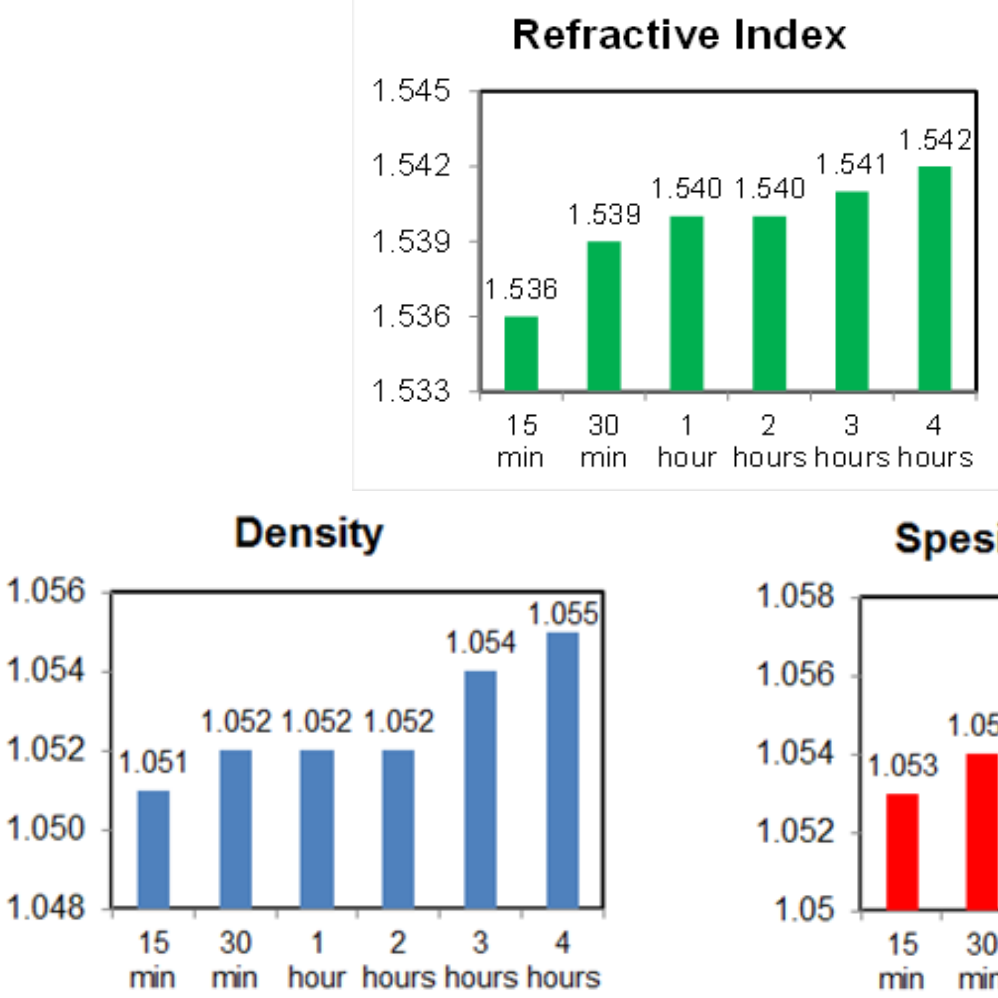

Spesific Gravity

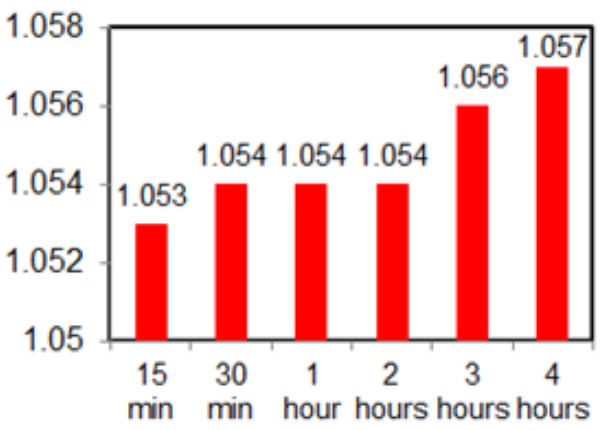

Fig. 3. The relationship between refractive index, density, specific gravity and synthesis times 
$1.01 \mathrm{~g} / \mathrm{mL} .^{12-13}$ From the observation data above, it was seen that the longer synthesis time generated aurantiol with greater refractive index, density, and specific gravity. This was due to the increasing quantity of methyl anthranilate in the aurantiol product, in which methyl anthranilate had the biggest density. So it can be concluded that the duration of synthesis time was directly proportional to the refractive index, density and specific gravity of the aurantiol product.

Table. 5: Refractive index, density and specific grafity of Aurantiol at various synthesis times

\begin{tabular}{lccc}
\hline Synthesis time & Refractive index & Density, g/mL & Specific gravity \\
\hline 15 minutes & 1.536 & 1.051 & 1.053 \\
30 minutes & 1.539 & 1.052 & 1.054 \\
1 hour & 1.540 & 1.052 & 1.054 \\
2 hours & 1.540 & 1.052 & 1.054 \\
3 hours & 1.541 & 1.054 & 1.056 \\
4 hours & 1.542 & 1.055 & 1.057 \\
\hline
\end{tabular}

\section{CONCLUSION}

Based on the results of this study, it can be concluded that the synthesis of aurantiol with simple condensation technique has been successfully done, with the highest aurantiol yield of $77.57 \%$ with an optimum synthesis time of 30 minutes to 1 hour. The longer synthesis time, it will produce aurantiol products with darker colors and greater refractive index, density and specific gravity. Therefore, this optimum synthesis time of 30 minutes to 1 hour can be used as a reference for the synthesis of aurantiol on an industrial scale.

\section{ACKNOWLEDGEMENT}

The authors wish to thank to Politeknik AKA Bogor, Ministry of Industry of Indonesia for providing the research fund. Partial support from PT. Nilam Widuri for GC-MS measurements is also acknowledged.

\section{REFERENCES}

1. Ansari, R.M.; Bhat, B.R. J. Chem. Sci. 2017, 129 (9), 1483-1490.

2. Da Silva,C.M.; da Silva, D.L.; Modolo, L.V.; Alves, R.B.; de Resende, M.A.; Cleide V.B. Martins, C.V.B.; de Fatima, A. J. Adv. Research, 2011, 2, 1-8

3. Nagesh, G.Y.; Mruthyunjayaswamy, B.H.M. J. Molecular Structure. 2015, 1085, 198

4. Herman, S.J. Fragrance Applications: A Survival Guide. 2002. Allured Publishing Corp. England.

5. Raikwar, K.; Agarwal, D.D. Orient. J. Chem., 2015, 31(1), 547-551

6. Dhokale N.T.; Karale, B.K.; Nagawade, A.V. Orient. J. Chem., 2017, 33(1), 165-172

7. Cortez-Pereira, C.S.; Baby, A.R.; Velasco, M.V.R. J. Cosmetic Dermatology, 2010, 9, 230-241

8. Sell, C.S. The Chemistry of Fragrances: From
Perfumer to Consumer. $2^{\text {nd }}$ Ed. RSC Publishing. Dorchester, 2006.

9. Campbell, D.I.; 1†, Dalgleish, J.K.; CotteRodriguez, I.; Maeno, S.; Cooks, R.G. Rapid Commun. Mass Spectrom. 2013, 27, 1828-1836

10. Herman, S. Cosmetic Science and Technology: Theoritical Principles and Applications., 2017, 8, 267-283

11. Swift, K. Current Topic in Flavours and Fragrance: Toward a New Millennium of Discovery. Springer. Netherlands, 2012.

12. Panten, J.; Surburg, H. Ullmann's Encyclopedia of Industrial Chemistry: Flavors and Fragrances, Wiley-VCH Verlag GmbH \& Co, 2002.

13. Bauer, K.; Garbe, D.; Surburg, H. Common Fragrance and Flavor Materials: Preparation, Properties and Uses, $3^{\text {rd }} \mathrm{Ed}$, Wiley-VCH Verlag GmbH, 1997. 